\title{
Hypoxia-reoxygenation treatment attenuates gestational diabetes mellitus
}

\author{
Xiuzhen Hou, Junfeng Zhang, Hehong Ma, Ming Li and Pei Wang \\ Division 1 of Obstetrics, Cangzhou Central Hospital, Cangzhou, Hebei, China
}

Correspondence should be addressed to J Zhang: zhangjf00116@163.com

\begin{abstract}
Background: Oxidative stress leads to insulin resistance and gestational diabetes mellitus (GDM). The nuclear factor erythroid 2-related factor 2 (Nrf2)/heme oxygenase-1 (HO-1) signaling is an important anti-oxidative stress pathway, which can be activated by hypoxia-reoxygenation (H/R) treatment. We aimed to demonstrate the effects of $H / R$ treatment on GDM symptoms as well as reproductive outcomes.

Methods: Pregnant C57BL/Ks] db/+ mice were used as a genetic GDM model. Plasma insulin and other biochemical indexes of plasma, insulin sensitivity, glucose intolerance, blood glucose and liver biochemical indexes were evaluated. Protein abundance of HO-1 and Nrf2 were assessed with Western blot.

Results: $\mathrm{H} / \mathrm{R}$ treatment markedly ameliorated $\beta$-cell insufficiency and glucose intolerance, suppressed oxidative stress in vivo, stimulated the activities of anti-oxidant enzymes, and led to improved reproductive outcomes. The beneficial effects of $H / R$ treatment were mechanistically mediated via the restoration of $\mathrm{Nrf2/HO}-1$ anti-oxidant signaling pathway in the liver of GDM mice.

Conclusion: Our study, for the first time, suggests that $\mathrm{H} / \mathrm{R}$ treatment is a potentially novel therapeutic approach against GDM symptoms, by activating the Nrf2/HO-1 signaling pathway and inhibiting oxidative stress.
\end{abstract}
Key Words
- gestational diabetes mellitus
- oxidative stress
- Nrf2HO-1 signaling
- $\mathrm{db} /+$ mouse model
- hypoxia-reoxygenation treatment

\section{Introduction}

Gestational diabetes mellitus (GDM) is primarily resulted from insulin resistance and glucose intolerance during pregnancy, affecting $7 \%$ of pregnant women globally $(1,2)$. GDM causes higher risks of diabetes, obesity and premature cardiovascular system disease during pregnancy for the fetus as well as the mother $(2,3)$. GDM may also lead to deficits in fetal development, with $\sim 15-45 \%$ of babies born by diabetic women exhibiting macrosomia symptoms $(4,5)$. Therefore, investigation and development of effective treatments against GDM are of essential clinical value.

In order to sustain the fasting energy requirements during pregnancy, the endogenous production of glucose is increased by $\sim 30 \%$ in pregnant women at the late gestational stage (6). However, in women with GDM, $\beta$ cell dysfunction can clinically manifest as an increase in insulin resistance and results in hyperglycemia during pregnancy $(7,8)$. Following the increased insulin resistance, circulating lipids, including free fatty acids, triglycerides (TG), low-density lipoprotein (LDL) and total cholesterol (TCh), are all elevated $(9,10)$. The placenta is a highly vascularized structure, enriched with mitochondria and high in reactive oxygen species (ROS) production and metabolic rate. Therefore, pregnancy is regarded as a prediabetic state with greater oxidative stress $(11,12)$.

Oxidative stress, which is among the major factors contributing to the diabetes pathogenesis, exerts crucial functions in the development of insulin resistance (13). Several reports have shown the manifestation of oxidative stress following GDM diagnosis $(14,15,16,17,18,19)$.
This work is licensed under a Creative Commons Attribution-NonCommercial 4.0 International License. ded from Bioscientifica.com at 04/26/2023 06:51:43AM 
In GDM patients, the serum malondialdehyde (MDA) level was increased whereas glutathione peroxidase (GPx) was reduced at 26-32 weeks of gestation (16). Toescu et al. showed that levels of lipids, as well as the lipid hydroperoxide activities, were elevated in women with GDM at late gestational stage (17). Levels of protein carbonyl content, plasma superoxide dismutase (SOD) and placental 8-isoprostane were all increased in pregnant women with GDM (15). The liver is the largest internal organ in the human body and is responsible for the metabolism of endogenous molecules as well as xenobiotics to maintain metabolic homeostasis (20). Many free radicals, for instance reactive sulfur species, reactive nitrogen species, and ROS, are the products of liver metabolism. When there is disruption in the balanced free radical production, oxidative stress is generated, which may result in liver damage and dysfunction, as well as hyperglycemia $(21,22)$. Several investigations have suggested that there is a strong association between liver metabolic dysfunction-induced oxidative stress and GDM or type 2 diabetes $(20,21,23,24)$. Thus, it is important to demonstrate the relationship between GDM and oxidative stress in the liver. Screening and development of novel anti-oxidants that alleviate oxidative stress and improve liver functions may provide valuable strategies for treating GDM.

The hypoxia-reoxygenation $(\mathrm{H} / \mathrm{R})$ treatment is recently reported to exhibit anti-oxidative efficacy in rodent models by activating nuclear factor erythroid 2-related factor 2 (Nrf2) (25). The nuclear transcription factor Nrf2 is an essential anti-oxidative regulator that maintains the redox state and defends against intracellular oxidative stress (26). We therefore investigated the effect of $\mathrm{H} / \mathrm{R}$ treatment in attenuating GDM symptoms using the pregnant $\mathrm{C} 57 \mathrm{BL} / \mathrm{KsJ} \mathrm{db} /+$ mouse model, as well as potential involvement of Nrf2 in this process.

\section{Materials and methods}

\section{GDM mouse model}

All experiments involving the use of mice were conducted in compliance with the Guide for the Care and Use of Laboratory Animals (8th edition, NIH), and obtained approval from the CANGZHOU CENTRAL HOSPITAL Animal Care and Use Committee. All measures were taken to minimize unnecessary suffering of the animals. C57BL/ KsJ wild-type (WT) and db/+ female mice (8-week old) were obtained from Shanghai Laboratory Animal Center
(Shanghai, China) and used in the current study as the GDM mouse model (27). The animals were housed under standard rearing conditions (12 h light:12 h darkness cycle), and allowed access to food and water ad libitum. At 10 weeks of age, female mice were individually mated with WT male mice, and on the next morning, designated gestation day (GD) 0, mice were checked for the presence of a copulatory plug to confirm successful mating.

\section{H/R treatment}

Pregnant female mice were then randomly assigned to various treatment groups with 12 mice per group. H/R treatment started on GD 0, and was conducted once per day till full term delivery. For the H/R treatment group, mice were first subjected to hypoxic insult with $6 \% \mathrm{O}_{2}$ for $1 \mathrm{~h}$, followed by reoxygenation with $21 \% \mathrm{O}_{2}$ for another $1 \mathrm{~h}$, as previously described (25). For the control group, mice were housed with constant $21 \% \mathrm{O}_{2}$.

\section{Glucose tolerance test (GTT) and insulin tolerance test (ITT)}

GTT and ITT were performed on GD 15. For GTT, mice, after $6 \mathrm{~h}$ fasting, received intraperitoneal (i.p.) injections of glucose at $2 \mathrm{~g}$ per $\mathrm{kg}$ body weight. Blood samples at 0,30 and 60 min following glucose administration were obtained from the tail via capillary tubes. For ITT, mice were fasted for $6 \mathrm{~h}$ and given i.p. insulin at $0.75 \mathrm{U}$ per $\mathrm{kg}$ body weight. At 0, 30 and 60 min following insulin injections, blood samples were similarly collected.

\section{Serum glucose, serum insulin and body weight}

At GD 0, 10 and 20, serum glucose and insulin levels as well as body weight were examined. Non-fasting samples of the blood were collected through tail vein, and the level of serum glucose was assessed using a glucometer (Lifescan Surestep). Serum insulin level was determined with UltraSensitive Mouse Insulin ELISA Kit (EMINS, Thermo Fisher Scientific). A top-loading balance (Fisher Scientific) was used to measure body weight.

\section{Liver dissection}

Six pregnant mice were sacrificed on GD 20, and blood and liver samples were harvested. Meanwhile, the other six mice were saved until completion of the pregnancy to collect the livers of the offspring after birth, which were dissected as previously established (28). For liver

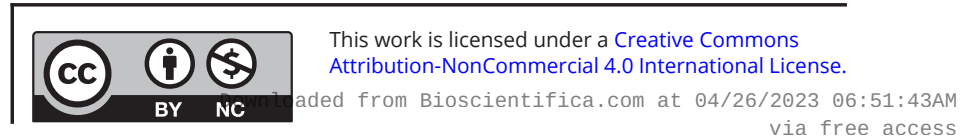


collection, mice were deeply anesthetized with a cocktail of $10 \mathrm{mg} / \mathrm{kg}$ acepromazine, $100 \mathrm{mg} / \mathrm{kg}$ xylazine and 100 $\mathrm{mg} / \mathrm{kg}$ ketamine. The abdominal cavity was cut open to expose the portal vein, through which an insulin bolus $(10 \mathrm{U} / \mathrm{kg}$ diluted in $100 \mu \mathrm{L}$ saline) was delivered. The livers were dissected immediately and stored at $-80^{\circ} \mathrm{C}$ until later use.

\section{Biochemical indexes analyses}

For measurement of blood indexes, GTT and ITT were examined as described previously (after $6 \mathrm{~h}$ fasting), while other biomedical indexes were measured under fed conditions. Female WT and db/+ mice were sacrificed on GD 20. Samples of blood were centrifuged at $1000 \boldsymbol{g}$ for 10 $\min$ at $4^{\circ} \mathrm{C}$ to collect serum samples, which were frozen at $-80^{\circ} \mathrm{C}$ for subsequent analyses. Liver tissues were collected and frozen at $-80^{\circ} \mathrm{C}$ for assessments of biochemical indexes. The TCh, LDL, high-density lipoprotein (HDL), MDA and TG levels were evaluated with Total Cholesterol Assay Kit (STA-384, Cell Biolabs), LDL/VLDL and HDL Cholesterol Assay Kit (STA-391, Cell Biolabs), Lipid Peroxidation MDA Assay Kit (S0131, Beyotime, Shanghai, China), and Serum Triglyceride Quantification Kit (STA396, Cell Biolabs), respectively. Atherogenic index was determined as previously established (29). Preparation of liver lysates was conducted following previously described protocol (27). The MDA, GPx, SOD, catalase (CAT), and glutathione (GSH) levels in the liver were determined using Lipid Peroxidation MDA Assay Kit (S0131), Total Glutathione Peroxidase Assay Kit (S0058), Total Superoxide Dismutase Assay Kit with NBT (S0109), Catalase Assay Kit (S0051), and Glutathione Reductase Assay Kit (S0055), obtained from Beyotime Biotechnology (Shanghai, China), respectively.

\section{Western blot}

Samples of liver tissues $(500 \mathrm{mg}$ ) were homogenized on ice using a cell strainer $(40 \mu \mathrm{m})$ with $2 \mathrm{~mL}$ cold buffer A (in mM: 10 Tris- $\mathrm{HCl}$ at $\mathrm{pH} 7.4,250$ sucrose, and $5 \mathrm{MgCl}_{2}$ ).
Liver lysates were first centrifuged at $4^{\circ} \mathrm{C}$ for $15 \mathrm{~min}$ at $500 \mathrm{~g}$. The resulted pellets were rinsed with buffer $\mathrm{A}$ again and then resuspended gently in eight volumes of buffer B (in $\mathrm{mM}$ : 10 Tris- $\mathrm{HCl}$ at $\mathrm{pH}=7.4,2000$ sucrose, and $1 \mathrm{MgCl}_{2}$ ). Next, the mixture was centrifuged at $4^{\circ} \mathrm{C}$ for $30 \mathrm{~min}$ at $16,000 \mathrm{~g}$, and the brownish upper layer was carefully discarded to collect the white pellet (the nuclei) in the bottom layer. The nuclei lysates were then examined through immunoblotting as previously described (22). Mouse Heme oxygenase-1 (HO-1) (1:1000, \#ab13248) and Nrf2 (1:1000, \#ab76026) primary antibodies were purchased from Abcam; Histone-3 antibody (1:2000, \#9715) was purchased from CST, Inc. (Danvers, USA).

\section{Statistical analysis}

Statistical analyses were performed with GraphPad Prism (https://www.graphpad.com/). One-way or twoway ANOVA followed by a Bonferroni post hoc multiple comparison test was employed to assess the differences between groups. The data were expressed as mean \pm S.D. $P<0.05$ was regarded as statistically significant difference.

\section{Results}

\section{H/R treatment attenuates GDM symptoms in pregnant $d b /+$ mice}

We first examined the effect of H/R treatment on GDM symptoms in pregnant $d b /+$ mice, in terms of steady state blood glucose and insulin levels during pregnancy. It was found that body weight gains throughout the pregnancy in all three groups were nearly identical (Fig. 1A), suggesting the $H / R$ treatment didn't cause any general adverse effect on pregnancy. Next, in WT females, blood glucose levels were stable on GD 0, 10 and 20 (Fig. 2B); whereas $d b /+$ female mice exhibited markedly increased levels of blood glucose, which is the characteristic hyperglycemic symptom of GDM. In contrast, in $d b /+$ females treated with $\mathrm{H} / \mathrm{R}$, blood glucose remained at similar levels as the WT group during the entire pregnancy, suggesting an
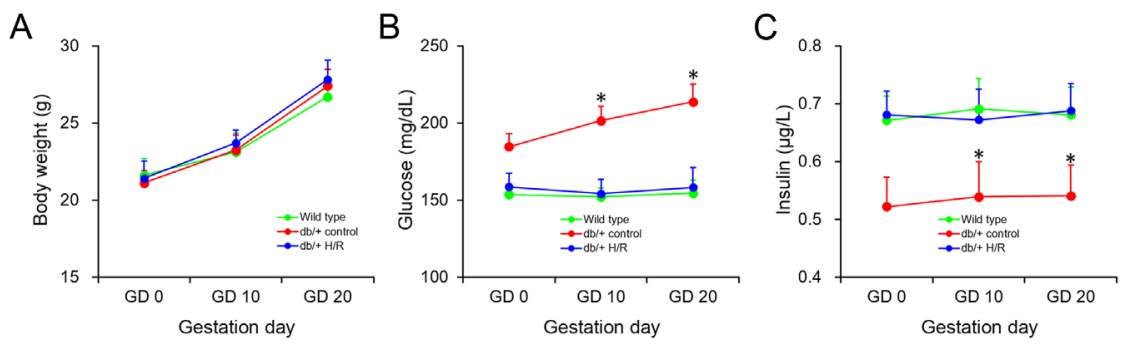

\section{Figure 1}

H/R treatment attenuates GDM symptoms in pregnant $d b /+$ mice. Maternal body weight (A), and serum glucose (B) and insulin levels (C) were measured on gestation day (GD) 0,10 and 20 in wild type, $d b /+$ control and $d b /+\mathrm{H} / \mathrm{R}$ mice. Data were shown in mean \pm s.D. $(n=12)$. $* P<0.05$, between ' $d b /+\mathrm{H} / \mathrm{R}^{\prime}$ and either 'Wild type' or ' $d b /+$ control' groups at the same time point. https://ec.bioscientifica.com https://doi.org/10.1530/EC-20-0555 (c) 2021 The authors Published by Bioscientifica Ltd
This work is licensed under a Creative Commons Attribution-NonCommercial 4.0 International License. ded from Bioscientifica.com at 04/26/2023 06:51:43AM via free access 
A

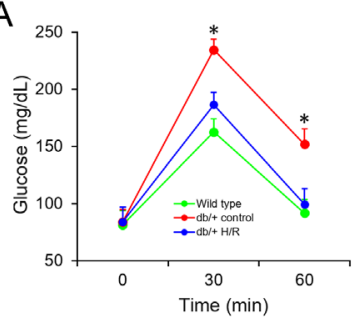

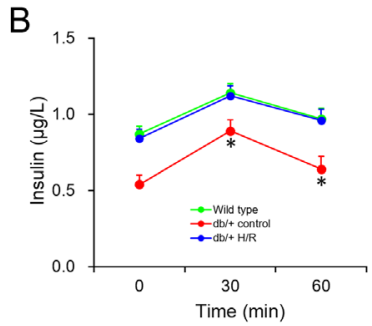

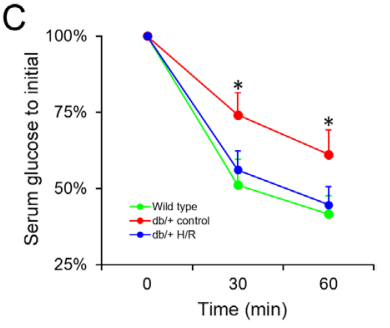

Figure 2

$\mathrm{H} / \mathrm{R}$ treatment improves glucose and insulin tolerance in pregnant $d b /+$ mice. Effects of $H / R$ treatment on serum glucose $(A)$ and insulin (B) levels during intraperitoneal glucose tolerance test in wild type, $d b /+$ control and $d b /+\mathrm{H} / \mathrm{R}$ mice on GD 15. (C) Effects of $H / R$ treatment on serum glucose level during intraperitoneal insulin tolerance test in wild type, $d b /+$ control and $d b /+$ $H / R$ mice on GD 15. Data were shown in mean \pm S.D. $(n=12) . * P<0.05$, between ' $d b /+\mathrm{H} / \mathrm{R}^{\prime}$ and either ' $W T^{\prime}$ ' or ' $d b /+$ control' groups at the same time point. alleviation of hyperglycemia by $\mathrm{H} / \mathrm{R}$ treatment. Likewise, steady state levels of insulin in $d b /+$ mice were substantially lower compared with the WT group, and fully restored in the group receiving $\mathrm{H} / \mathrm{R}$ treatment (Fig. 1C).

\section{H/R treatment improves glucose and insulin tolerance in pregnant $d b /+$ mice}

We next conducted the GTT test in all three groups on GD 10 . In comparison to WT mice, pregnant $d b /+$ female mice showed marked glucose intolerance, as indicated by the prominent elevation of glucose levels following the initial injection of glucose (Fig. 2A, 30 and $60 \mathrm{~min}$ ), while H/R treatment in the $d b /+$ females largely ameliorated such glucose intolerance. Meanwhile, insulin levels in the $d b /+$ mice were greatly reduced throughout the testing period $(0$, 30 and $60 \mathrm{~min}$ ) in comparison with the WT mice (Fig. 2B), likely contributing to the glucose intolerant phenotype. Most importantly, insulin response was restored by $\mathrm{H} / \mathrm{R}$ treatment to the same level as the WT controls. In comparison with the GTT that evaluates the complete outcome of insulin secretion and glucose disposal, the ITT directly measures the ability of insulin to promptly promote the degradation of glucose (30). Hence, we next conducted the ITT in all three groups on GD 10 (Fig. 2C). Expectedly, blood glucose levels in the $d b /+$ females were greatly higher than those of WT after the initial insulin administration, indicating an insulin resistant phenotype. Further, H/R treatment in the $d b /+$ mice led to a noticeable reduction of the glucose level to similar levels as the WT. Collectively, these results suggested that $\mathrm{H} / \mathrm{R}$ treatment attenuated acute intolerance to glucose and insulin in pregnant $d b /+$ mice.

\section{H/R treatment improves biochemical indexes in pregnant $d b /+$ mice}

To further demonstrate the beneficial metabolic effects of $\mathrm{H} / \mathrm{R}$ treatment, several biochemical indexes in the serum of pregnant $d b /+$ mouse were assessed on GD 20, a late stage in pregnancy. As shown in Fig. 3, compared to $d b /+$ mice, the serum TG, TCh and LDL were significantly reduced in pregnant $d b /+$ females with $\mathrm{H} / \mathrm{R}$ treatment (Fig. 3A, B and D). Interestingly, HDL, the 'good' cholesterol that clears excess cholesterol from the arteries, was remarkably elevated in mice receiving $\mathrm{H} / \mathrm{R}$ treatment compared with the untreated controls (Fig. 3C). Further, the atherogenic index in pregnant
A
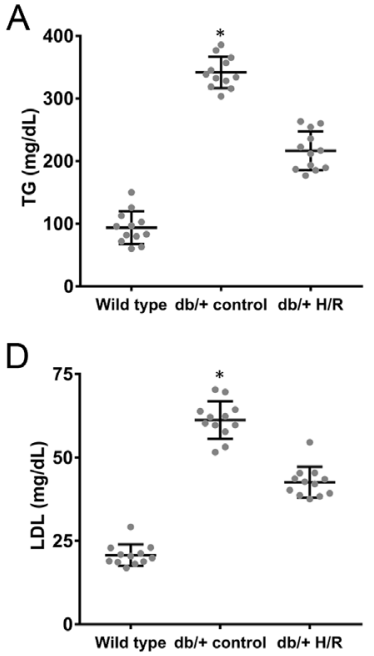

B

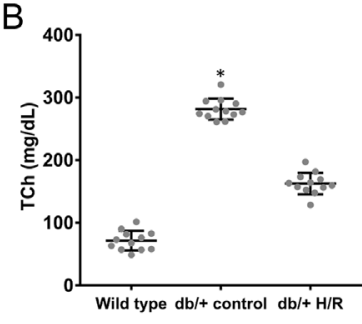

E

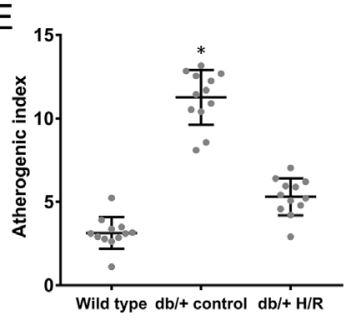

C

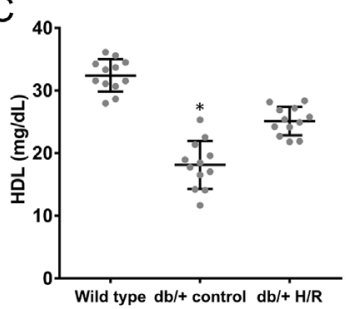

\section{Figure 3}

$H / R$ treatment improves biochemical indexes in pregnant $d b /+$ mice. (A) Serum triglyceride (TG), (B) total serum cholesterol (TCh), (C) serum high-density lipoprotein (HDL), (D) serum low-density lipoprotein (LDL) and (E) atherogenic index were measured in wild type, $d b /+$ control and $d b /+H / R$ mice on GD 20. Data were shown in mean \pm s.D. $(n=12)$. ${ }^{*} P<0.05$, between ' $d b /+\mathrm{H} / \mathrm{R}^{\prime}$ and either 'Wild type' or ' $d b /+$ control' groups. https://ec.bioscientifica.com https://doi.org/10.1530/EC-20-0555 (c) 2021 The authors Published by Bioscientifica Ltd
This work is licensed under a Creative Commons Attribution-NonCommercial 4.0 International License. ded from Bioscientifica.com at 04/26/2023 06:51:43AM 
$d b /+$ mice with $\mathrm{H} / \mathrm{R}$ treatment was lower than that in the controls (Fig. 3E). These findings showed that H/R treatment improved biochemical indexes and promoted metabolic homeostasis in GDM mice at the late stage of pregnancy.

\section{H/R treatment relieves maternal oxidative stress in pregnant $d b /+$ mice}

The maternal oxidative stress is a main factor contributing to insulin resistance and exerts crucial roles in the development of GDM. In the current study, we assessed the oxidative stress-related parameters in GDM mice with or without H/R treatments at GD 20. We first examined the activities of first line defense anti-oxidants in the liver, such as SOD, CAT and GPx. The results showed that H/R treatment induced noticeable increase in the activities of those defense anti-oxidants in pregnant $d b /+$ mice in comparison with untreated $d b /+$ controls and the positive controls (Fig. 4A, B and D). In addition, the levels of GSH, an essential anti-oxidant to prevent oxidative damages, were greatly increased in the livers of $d b /+$ mice treated with H/R (Fig. 4C). Finally, both the serum and liver levels of MDA were also upregulated in $d b /+$ mice compared with the WT group, which were markedly inhibited by the H/R treatment (Fig. 5E and F). These findings demonstrated that $H / R$ treatment alleviated the maternal oxidative stress in pregnant GDM mice.

\section{H/R treatment improves reproductive outcome of pregnant $d b /+$ mice}

Reduced fetal survival, as indicated by fewer fetuses $(31,32)$, is among the major adverse impacts of GDM. Further, the average offspring birth weight was reportedly increased by $5-8 \%$ in $d b /+$ GDM mice $(30,33)$. Thus, we next examined whether $H / R$ treatment could lead to improved reproductive outcomes in GDM females. Offspring was counted at birth for each female mouse from the WT, $d b /+$ control and $d b /+\mathrm{H} / \mathrm{R}$ groups (Fig. 5A). Six WT female mice delivered 40 litters, and the six female mice of the $d b /+$ group delivered 25 litters. By contrast, the six females in the $d b /+\mathrm{H} / \mathrm{R}$ group gave birth to 35 litters. We further compared the birth weight of the offspring in all groups (Fig. 5B), and the result showed that, in consistence with prior reports $(30,33)$, offspring born by $d b /+$ females were on average significantly heavier than those in the WT group, whereas birth weight of offspring in the $d b /+\mathrm{H} / \mathrm{R}$ group was nearly the same as WT controls. These data clearly suggested that H/R treatment improved the reproductive outcomes of GDM female mice.

\section{H/R treatment elevates Nrf2 activation and HO-1 expression in pregnant $d b /+$ mice}

As the Nrf2/HO-1 signaling pathway reportedly functions as a critical transcriptional regulator of antioxidant genes to restore redox homeostasis $(25,26)$, we investigated the effects of $\mathrm{H} / \mathrm{R}$ treatment on the Nrf2/ HO-1 signaling pathway in the livers of pregnant mice using Western blot. Compare to WT mice, a lower level of nuclear Nrf2 was observed in $d b /+$ mice (Fig. 6A). Consistently, the Nrf2-dependent gene, HO-1, which clears out toxic heme to protect against oxidative injuries, was also reduced in $d b /+$ mice (Fig. 6B). Importantly, H/R treatment dramatically elevated the nuclear expression of Nrf2 as well as HO-1 (Fig. 6A and B). These results showed that $\mathrm{H} / \mathrm{R}$ treatment likely stimulated the Nrf2/ HO-1 signaling pathway and enhanced the oxidative responsive capability in GDM mice.
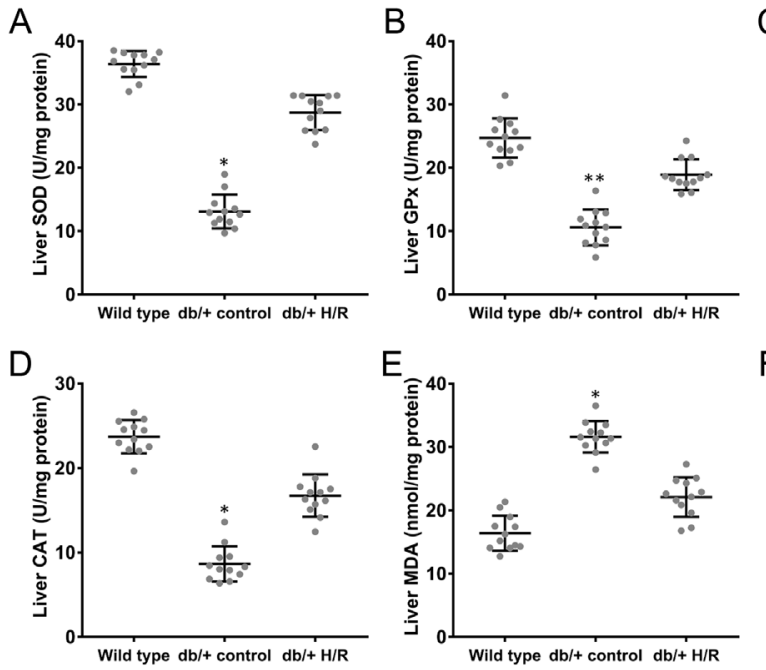
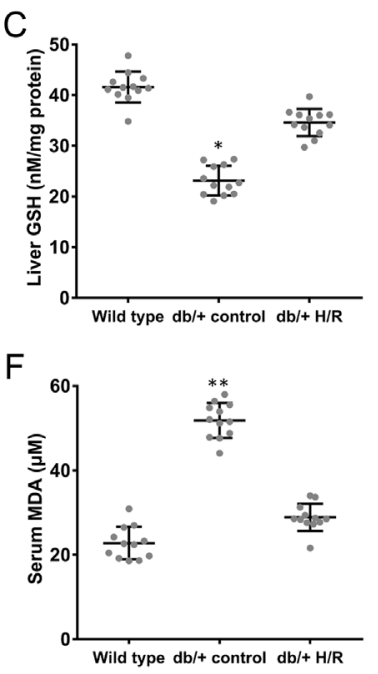

Figure 4

H/R treatment relieves maternal oxidative stress in pregnant $d b /+$ mice. Liver levels of (A) superoxide dismutase (SOD), (B) glutathione peroxidase (GPx), (C) glutathione (GSH), (D) catalase (CAT), and serum (A) and liver (B) levels of MDA contents were measured by ELISA in wild type, $d b /+$ control and $d b /+\mathrm{H} / \mathrm{R}$ mice on GD 20. Data were shown in mean \pm S.D. $(n=6) .{ }^{*} P<0.05$, $* \star P<0.01$, between ' $d b /+H / R^{\prime}$ and either 'Wild type' or 'db/+ control' groups. https://ec.bioscientifica.com https://doi.org/10.1530/EC-20-0555 (c) 2021 The authors Published by Bioscientifica Ltd

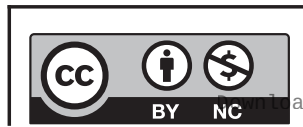

This work is licensed under a Creative Commons Attribution-NonCommercial 4.0 International License. ded from Bioscientifica.com at 04/26/2023 06:51:43AM via free access 
A
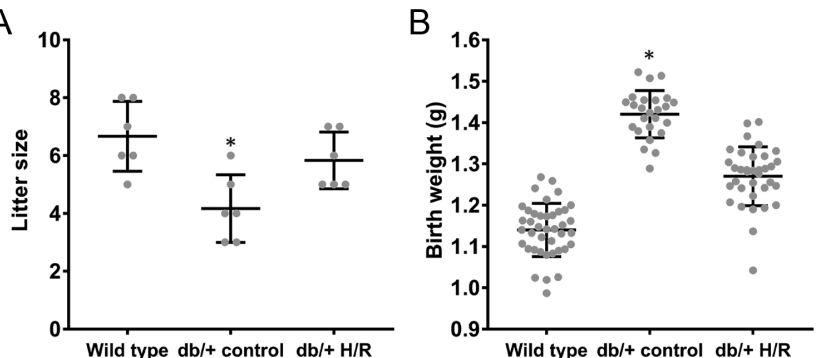

Figure 5

$\mathrm{H} / \mathrm{R}$ treatment improves reproductive outcome of pregnant $d b /+$ mice. (A) Litter size and $(B)$ body weight at birth of offsprings born by each female mouse from wild type, $d b /+$ control and $d b /+$ H/R groups. Data were shown in mean \pm S.D. $(n=6)$. $* P<0.05$, between ' $d b /+H / R^{\prime}$ and either 'Wild type' or ' $d b /+$ control' groups.

\section{Discussion}

GDM is an emerging world-wide public health concern, affecting $7 \%$ of pregnant women around the globe $(1,2)$. The majority of GDM patients exhibit chronic hyperglycemia and insulin resistance (2), indicating the similarity between diabetes and GDM with regard to cause as well as symptoms. Oxidative stress is proposed to play a causative role in the development of diabetes and insulin resistance. Therefore, anti-oxidative pathways, such as Nrf2/HO-1 discovered in this study, with active involvement in dyslipidemia and diabetes, are extremely likely to possess similar properties in preventing and treating GDM. Metformin and insulin are the two major drugs prescribed to treat GDM; however, the clinical practice of insulin is hindered by the inconvenient administration route as well as the potential to become hypoglycemic and to gain weight $(1,3,5)$. Our data demonstrated that $\mathrm{H} / \mathrm{R}$ treatment markedly alleviated

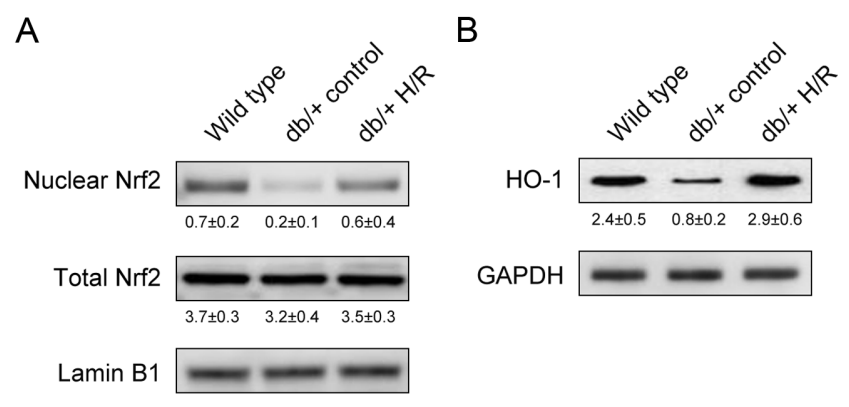

\section{Figure 6}

$\mathrm{H} / \mathrm{R}$ treatment elevates Nrf2 activation and $\mathrm{HO}-1$ expression in pregnant $\mathrm{db} /+$ mice. Western blot analysis of (A) total and nuclear protein levels of $\mathrm{Nrf2}$, and (B) HO-1 protein level in maternal liver tissues of wild type, $d b /+$ control and $d b /+H / R$ mice on GD 20. Representative images of the blots, from three independent biological repeats, were shown, with quantification indicated as relative to the loading control below each blot as mean \pm S.D.
GDM symptoms via the activation of anti-oxidant enzymes (SOD, GPx and CAT) and restoration of the Nrf2/HO-1 signaling pathway. We also found that H/R treatment dramatically improved glucose intolerance as well as $\beta$-cell insufficiency in pregnant GDM mice.

Our results are the first to illustrate that $\mathrm{H} / \mathrm{R}$ treatment possess the capacity to ameliorate GDM symptoms by reducing hepatic oxidative stress in a mouse model. We further demonstrated the molecular mechanism underlying the positive effects of $\mathrm{H} / \mathrm{R}$ treatment in pregnant $d b /+$ mice. We discovered that $\mathrm{H} / \mathrm{R}$ treatment restored the activities of Nrf2/HO-1 signaling pathway in the liver and improved atherogenic index in GDM mice. Nrf2 is considered as an oxidative stress sensor (34), and in the presence of ROS and the cytosolic Nrf2 repressor Keap1, it undergoes structural changes to dissociate from the Nrf2-Keap1 complex, which allows Nrf2 to translocate into the nucleus to initiate transcription of genes with an anti-oxidant response element in their promoter (35). HO-1, a target of Nrf2, exerts pivotal beneficial functions in diseases associated with oxidative stress (36). A recent study demonstrated that HO-1 could be upregulated by various natural compounds (37). In particular in HepG2 cells, HO-1 upregulation through Nrf2-transduction and p38 inactivation (38) exhibited protective effects against oxidative damage through the Keap1/Nrf2-dependent signaling pathway (39). Our results revealed that $H / R$ treatment could prevent oxidative stress, in agreement with earlier report (25). H/R treatment has also been shown to protect the blood-brain barrier against oxidative stress by activating the Nrf2 signaling to regulate inflammation-related genes such as GSH (25). H/R-induced injury was also implicated in hepatocytes by promoting apoptosis and oxidative stress through regulating Keap1/Nrf2 signaling (40). In patients with type 2 diabetes, Nrf2 is positively correlated with Th2 cytokines and is able to partially restore the stress cytokine-inhibited insulin secretion in pancreatic $\beta$-cells (41). Importantly, introduction of Nrf2 in fetal endothelial cells was shown to improve the antioxidative capacity (42). The above-mentioned studies all pointed to the critical role of $\mathrm{Nrf} 2$ in $\mathrm{H} / \mathrm{R}$ treatment or injury models, as well as its role in diabetic symptoms, therefore highlighted the importance of investigating the Nrf2-related pathways in the pathogenesis of not only diabetes but also GDM. The current study, together with the aforementioned findings, suggested that the Nrf2 anti-oxidative pathway is critical for the development of GDM, supporting a promising role of Nrf2 as a biomarker for the diagnosis or treatment of GDM.

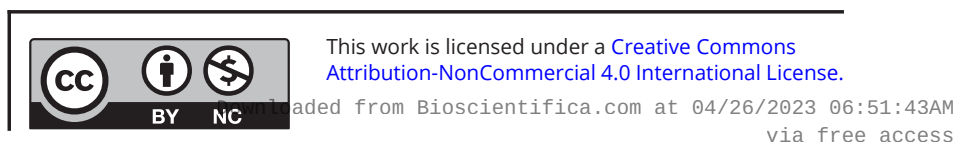


Fetal macrosomia, referring to birth weight above $90 \%$ for the gestational age, is one of the main adverse outcomes of $\operatorname{GDM}(2,5)$. In expecting mothers with GDM, blood glucose of abnormal high levels feeds into the fetal circulation via the placenta, forcing the fetal pancreas to react to the hyperglycemia and often leading to hyperinsulinemia. The high levels of glucose as well as insulin result in excess storage of protein and fat in the fetus, finally causing macrosomia $(43,44)$. Fewer offspring number is another typical phenotype in $\operatorname{GDM}$ mice $(5,30)$, as consistently observed in the current study. Of note, the $H / R$ treatment rescued the defects in offspring number in $d b /+$ mice. Additionally, birth weight of offspring born by GDM females treated with $\mathrm{H} / \mathrm{R}$ was reduced by $\sim 9 \%$ compared with the controls born by untreated GDM mothers. Altogether, our study demonstrated that $\mathrm{H} / \mathrm{R}$ treatment ameliorated the $\beta$-cell insufficiency and glucose intolerance, alleviated symptoms of GDM, and improved the reproductive outcomes by stimulating anti-oxidant enzymes and restoring the $\mathrm{Nrf} 2 / \mathrm{HO}-1$ signaling pathway.

\section{Conclusion}

In conclusion, our findings in the current study provided the first evidence of the therapeutic potential of $H / R$ treatment against GDM using $d b /+$ mice as a mouse GDM model. H/R treatment substantially alleviated $\beta$-cell insufficiency and glucose intolerance, relieved dyslipidemia and oxidative stress, enhanced the activities of anti-oxidant enzymes, and eventually improved fetal development. This effect of $\mathrm{H} / \mathrm{R}$ treatment was mechanistically mediated through restoration of the hepatic Nrf2/HO-1 anti-oxidant signaling in GDM mice. Our data indicate that $\mathrm{H} / \mathrm{R}$ treatment could serve as a potential therapeutic strategy for combating diabetes as well as GDM.

\section{Declaration of interest}

The authors declare that there is no conflict of interest that could be perceived as prejudicing the impartiality of the research reported.

\section{Funding}

This work did not receive any specific grant from any funding agency in the public, commercial, or not-for-profit sector.

\section{References}

1 American Diabetes Association. Gestational diabetes mellitus. Diabetes Care 200427 (Supplement 1) S88-S90. (https://doi. org/10.2337/diacare.27.2007.s88)
2 McIntyre HD, Catalano P, Zhang C, Desoye G, Mathiesen ER \& Damm P. Gestational diabetes mellitus. Nature Reviews: Disease Primers 20195 47. (https://doi.org/10.1038/s41572-019-0098-8)

3 Xiang AH, Wang X, Martinez MP, Getahun D, Page KA, Buchanan TA \& Feldman K. Maternal gestational diabetes mellitus, Type 1 diabetes, and Type 2 diabetes during pregnancy and risk of ADHD in offspring. Diabetes Care 201841 2502-2508. (https://doi.org/10.2337/dc18-0733)

4 Buchanan TA \& Xiang AH. Gestational diabetes mellitus. Journal of Clinical Investigation 2005115 485-491. (https://doi.org/10.1172/ JCI200524531)

5 Kc K, Shakya S \& Zhang H. Gestational diabetes mellitus and macrosomia: a literature review. Annals of Nutrition and Metabolism 201566 (Supplement 2) 14-20. (https://doi.org/10.1159/000371628)

6 Catalano PM, Tyzbir ED, Wolfe RR, Roman NM, Amini SB \& Sims EA. Longitudinal changes in basal hepatic glucose production and suppression during insulin infusion in normal pregnant women. American Journal of Obstetrics and Gynecology 1992167 913-919. (https://doi.org/10.1016/s0002-9378(12)80011-1)

7 Catalano PM, Huston L, Amini SB \& Kalhan SC. Longitudinal changes in glucose metabolism during pregnancy in obese women with normal glucose tolerance and gestational diabetes mellitus. American Journal of Obstetrics and Gynecology 1999180 903-916. (https://doi.org/10.1016/s0002-9378(99)70662-9)

8 Buchanan TA. Pancreatic B-cell defects in gestational diabetes: implications for the pathogenesis and prevention of type 2 diabetes. Journal of Clinical Endocrinology and Metabolism 200186 989-993. (https://doi.org/10.1210/jcem.86.3.7339)

9 Homko C, Sivan E, Chen X, Reece EA \& Boden G. Insulin secretion during and after pregnancy in patients with gestational diabetes mellitus. Journal of Clinical Endocrinology and Metabolism 200186 568-573. (https://doi.org/10.1210/jcem.86.2.7137)

10 Toescu V, Nuttall SL, Martin U, Kendall MJ \& Dunne F. Oxidative stress and normal pregnancy. Clinical Endocrinology 200257 609-613. (https://doi.org/10.1046/j.1365-2265.2002.01638.x)

11 Morris JM, Gopaul NK, Endresen MJ, Knight M, Linton EA, Dhir S, Anggard EE \& Redman CW. Circulating markers of oxidative stress are raised in normal pregnancy and pre-eclampsia. British Journal of Obstetrics and Gynaecology 1998105 1195-1199. (https://doi. org/10.1111/j.1471-0528.1998.tb09974.x)

12 Chen X \& Scholl TO. Oxidative stress: changes in pregnancy and with gestational diabetes mellitus. Current Diabetes Reports 20055 282-288. (https://doi.org/10.1007/s11892-005-0024-1)

13 Bloch-Damti A \& Bashan N. Proposed mechanisms for the induction of insulin resistance by oxidative stress. Antioxidants and Redox Signaling 20057 1553-1567. (https://doi.org/10.1089/ars.2005.7.1553)

14 Coughlan MT, Permezel M, Georgiou HM \& Rice GE. Repression of oxidant-induced nuclear factor-kappaB activity mediates placental cytokine responses in gestational diabetes. Journal of Clinical Endocrinology and Metabolism 200489 3585-3594. (https://doi. org/10.1210/jc.2003-031953)

15 Coughlan MT, Vervaart PP, Permezel M, Georgiou HM \& Rice GE. Altered placental oxidative stress status in gestational diabetes mellitus. Placenta 200425 78-84. (https://doi.org/10.1016/S01434004(03)00183-8)

16 Peuchant E, Brun JL, Rigalleau V, Dubourg L, Thomas MJ, Daniel JY, Leng JJ \& Gin H. Oxidative and antioxidative status in pregnant women with either gestational or type 1 diabetes. Clinical Biochemistry 200437 293-298. (https://doi.org/10.1016/j.clinbiochem.2003.12.005)

17 Zhang C, Williams MA, Sorensen TK, King IB, Kestin MM, Thompson ML, Leisenring WM, Dashow EE \& Luthy DA. Maternal plasma ascorbic acid (vitamin C) and risk of gestational diabetes mellitus. Epidemiology 200415 597-604. (https://doi.org/10.1097/01. ede.0000134864.90563.fa)

18 Castillo-Castrejon M \& Powell TL. Placental nutrient transport in gestational diabetic pregnancies. Frontiers in Endocrinology 20178 306. (https://doi.org/10.3389/fendo.2017.00306)

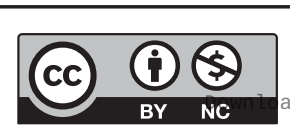

This work is licensed under a Creative Commons Attribution-NonCommercial 4.0 International License. ded from Bioscientifica.com at $04 / 26 / 2023$ 06:51:43AM 
19 Jamilian M, Mirhosseini N, Eslahi M, Bahmani F, Shokrpour M, Chamani M \& Asemi Z. The effects of magnesium-zinc-calcium-vitamin D co-supplementation on biomarkers of inflammation, oxidative stress and pregnancy outcomes in gestational diabetes. BMC Pregnancy and Childbirth 201919 107. (https://doi.org/10.1186/s12884-019-2258-y)

20 Zhao W, Zhang L, Zhang G, Varkaneh HK, Rahmani J, Clark C, Ryan PM, Abdulazeem HM \& Salehisahlabadi A. The association of plasma levels of liver enzymes and risk of gestational diabetes mellitus: a systematic review and dose-response meta-analysis of observational studies. Acta Diabetologica 202057 635-644. (https:// doi.org/10.1007/s00592-019-01458-8)

21 Ajmera VH, Gunderson EP, VanWagner LB, Lewis CE, Carr JJ \& Terrault NA. Gestational diabetes mellitus is strongly associated with non-alcoholic fatty liver disease. American Journal of Gastroenterology 2016111 658-664. (https://doi.org/10.1038/ajg.2016.57)

22 Guo L, Zhang P, Chen Z, Xia H, Li S, Zhang Y, Kobberup S, Zou W $\&$ Lin JD. Hepatic neuregulin 4 signaling defines an endocrine checkpoint for steatosis-to-NASH progression. Journal of Clinical Investigation 2017127 4449-4461. (https://doi.org/10.1172/JCI96324)

23 Foghsgaard S, Andreasen C, Vedtofte L, Andersen ES, Bahne E, Strandberg C, Buhl T, Holst JJ, Svare JA, Clausen TD, et al. Nonalcoholic fatty liver disease is prevalent in women with prior gestational diabetes mellitus and independently associated with insulin resistance and waist circumference. Diabetes Care 201740 109-116. (https://doi.org/10.2337/dc16-1017)

24 Gao J, Xiao H, Li J, Guo X, Cai W \& Li D. N-3 polyunsaturated fatty acids decrease long-term diabetic risk of offspring of gestational diabetes rats by postponing shortening of hepatic telomeres and modulating liver metabolism. Nutrients 201911 1699. (https://doi. org/10.3390/nu11071699)

25 Ibbotson K, Yell J \& Ronaldson PT. Nrf2 signaling increases expression of ATP-binding cassette subfamily C mRNA transcripts at the bloodbrain barrier following hypoxia-reoxygenation stress. Fluids and Barriers of the CNS 2017 14 6. (https://doi.org/10.1186/s12987-017-0055-4)

26 Hichor M, Sundaram VK, Eid SA, Abdel-Rassoul R, Petit PX, Borderie D, Bastin J, Eid AA, Manuel M, Grenier J, et al. Liver X receptor exerts a protective effect against the oxidative stress in the peripheral nerve. Scientific Reports 20188 2524. (https://doi. org/10.1038/s41598-018-20980-3)

27 Song H, Xu Y, Yang X, Rong X, Wang Y \& Wei N. Tertiary butylhydroquinone alleviates gestational diabetes mellitus in C57BL/KsJ-Lep $\mathrm{db} /+$ mice by suppression of oxidative stress. Journal of Cellular Biochemistry 2019120 15310-15319. (https://doi. org/10.1002/jcb.28798)

28 Yamashita H, Shao J, Qiao L, Pagliassotti M \& Friedman JE. Effect of spontaneous gestational diabetes on fetal and postnatal hepatic insulin resistance in Lepr(db/+) mice. Pediatric Research 200353 411-418. (https://doi.org/10.1203/01.PDR.0000049667.58071.7D)

29 Suman RK, Mohanty IR, Maheshwari U, Borde MK \& Deshmukh YA. Natural dipeptidyl peptidase-IV inhibitor mangiferin mitigates diabetes- and metabolic syndrome-induced changes in experimental rats. Diabetes, Metabolic Syndrome and Obesity: Targets and Therapy 20169 261-272. (https://doi.org/10.2147/DMSO.S109599)

30 Yamashita H, Shao J, Ishizuka T, Klepcyk PJ, Muhlenkamp P, Qiao L, Hoggard N \& Friedman JE. Leptin administration prevents spontaneous gestational diabetes in heterozygous Lepr $(\mathrm{db} /+)$ mice: effects on placental leptin and fetal growth. Endocrinology 2001142 2888-2897. (https://doi.org/10.1210/endo.142.7.8227)

31 Siemelink M, Verhoef A, Dormans JA, Span PN \& Piersma AH. Dietary fatty acid composition during pregnancy and lactation in the rat programs growth and glucose metabolism in the offspring. Diabetologia 200245 1397-1403. (https://doi.org/10.1007/s00125-002-0918-2)

32 Buckley AJ, Keseru B, Briody J, Thompson M, Ozanne SE \& Thompson $\mathrm{CH}$. Altered body composition and metabolism in the male offspring of high fat-fed rats. Metabolism: Clinical and Experimental 200554 500-507. (https://doi.org/10.1016/j.metabol.2004.11.003)

33 Lawrence S, Warshaw J \& Nielsen HC. Delayed lung maturation in the macrosomic offspring of genetically determined diabetic (db/+) mice. Pediatric Research 198925 173-179. (https://doi. org/10.1203/00006450-198902000-00019)

34 Wang X, Campos CR, Peart JC, Smith LK, Boni JL, Cannon RE \& Miller DS. Nrf2 upregulates ATP binding cassette transporter expression and activity at the blood-brain and blood-spinal cord barriers. Journal of Neuroscience 201434 8585-8593. (https://doi. org/10.1523/JNEUROSCI.2935-13.2014)

$35 \mathrm{Ma}$ Q. Role of nrf2 in oxidative stress and toxicity. Annual Review of Pharmacology and Toxicology 201353 401-426. (https://doi. org/10.1146/annurev-pharmtox-011112-140320)

36 Loboda A, Damulewicz M, Pyza E, Jozkowicz A \& Dulak J. Role of Nrf2/HO-1 system in development, oxidative stress response and diseases: an evolutionarily conserved mechanism. Cellular and Molecular Life Sciences 201673 3221-3247. (https://doi.org/10.1007/ s00018-016-2223-0)

37 Chen L, Gnanaraj C, Arulselvan P, El-Seedi H \& Teng H. A review on advanced microencapsulation technology to enhance bioavailability of phenolic compounds: based on its activity in the treatment of Type 2 diabetes. Trends in Food Science and Technology 201985 149-162. (https://doi.org/10.1016/j.tifs.2018.11.026)

38 Chen L, Teng H, Zhang KY, Skalicka-Wozniak K, Georgiev MI \& Xiao J. Agrimonolide and desmethylagrimonolide induced HO-1 expression in HepG2 cells through Nrf2-transduction and p38 inactivation. Frontiers in Pharmacology 20167 513. (https://doi. org/10.3389/fphar.2016.00513)

39 Chen L, Li K, Liu Q, Quiles JL, Filosa R, Kamal MA, Wang F, Kai G, Zou $\mathrm{X}$, Teng $\mathrm{H}$, et al. Protective effects of raspberry on the oxidative damage in HepG2 cells through Keap1/Nrf2-dependent signaling pathway. Food and Chemical Toxicology 2019133 110781. (https:// doi.org/10.1016/j.fct.2019.110781)

$40 \mathrm{Wu} \mathrm{H} \& \mathrm{Jia}$ L. Scutellarin attenuates hypoxia/reoxygenation injury in hepatocytes by inhibiting apoptosis and oxidative stress through regulating Keap1/Nrf2/ARE signaling. Bioscience Reports 201939 BSR20192501. (https://doi.org/10.1042/BSR20192501)

41 Sireesh D, Dhamodharan U, Ezhilarasi K, Vijay V, Ramkumar KM \& Association of NF-E2 Related Factor. (Nrf2) and inflammatory cytokines in recent onset type 2 diabetes mellitus. Scientific Reports 20188 5126. (https://doi.org/10.1038/s41598-018-22913-6)

42 Cheng X, Chapple SJ, Patel B, Puszyk W, Sugden D, Yin X, Mayr M, Siow RC \& Mann GE. Gestational diabetes mellitus impairs Nrf2mediated adaptive antioxidant defenses and redox signaling in fetal endothelial cells in utero. Diabetes 201362 4088-4097. (https://doi. org/10.2337/db13-0169)

43 Whyte K, Kelly H, O’Dwyer V, Gibbs M, O’Higgins A \& Turner MJ. Offspring birth weight and maternal fasting lipids in women screened for gestational diabetes mellitus (GDM). European Journal of Obstetrics, Gynecology, and Reproductive Biology 2013170 67-70. (https://doi.org/10.1016/j.ejogrb.2013.04.015)

44 Leng J, Li W, Zhang S, Liu H, Wang L, Liu G, Li N, Redman LM, Baccarelli AA, Hou L, et al. GDM women's pre-pregnancy overweight/ obesity and gestational weight gain on offspring overweight status. PLoS ONE 201510 e0129536. (https://doi.org/10.1371/journal.pone.0129536)

Received in final form 11 November 2020

Accepted 14 December 2020

Accepted Manuscript published online 15 December 2020 https://ec.bioscientifica.com https://doi.org/10.1530/EC-20-0555 (c) 2021 The authors Published by Bioscientifica Ltd

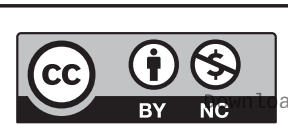

This work is licensed under a Creative Commons Attribution-NonCommercial 4.0 International License. ded from Bioscientifica.com at 04/26/2023 06:51:43AM 